\title{
Investigating the Transfer of Techniques for Electronic Technical Support Documentation from Aerospace to Machine Tools
}

\author{
Richard M. Greenough \\ David Williams
}

Dr Richard M Greenough

School of Industrial and Manufacturing Science, Cranfield University, Bedford, MK430AL $\underline{r}$. m.greenough@cranfield.ac.uk

Tel: 01234750111

Fax: 01234752159

Mr David Williams

GKN Aerospace Engineering Services

91 Preston Road, Yeovil, BA20 2DN

\begin{abstract}
This paper describes a scoping study that investigated the possible transfer of techniques for creation of electronic technical support documentation from the aerospace industry to the machine tool industry.

Electronic maintenance manuals have been supplied by aircraft manufacturers for the past 20 years with demonstrated benefits. Despite research that indicates the likelihood of similar benefits for machine tool users, the supply of electronic Technical Support Documentation (TSD) by machine tool manufacturers is rare, and the techniques for the creation of TSD are inefficient. This paper describes the relevant trends affecting the machine tool industry and the background to the use of electronic TSD in aerospace. Data was collected via interviews with technical authors, document users and software suppliers from both industry sectors, as well as a questionnaire and a workshop. The results were analysed to form a view of the potential for technology transfer over the next five years.
\end{abstract}

Keywords 
Technical documentation, aerospace industry, machine tools, maintenance.

\section{Introduction}

The operation and maintenance of complex equipment requires the use of several different types of technical document such as manuals, drawings and spares lists. Historically, machine tool builders have provided these documents as hardcopy, but electronic technical support documentation (TSD) provides various advantages over paper, for both the users and suppliers of machinery. Greenough et al. (2001) have shown how a hypermedia maintenance information system can be used to reduce troubleshooting time on an automated assembly machine, whilst Crowder et al. (2000) and Setchi and White (2003) have investigated the technical issues related to the preparation and use of hypermedia documentation to support machine maintenance. Despite this and similar research, today's machine tool manufacturers make little use of the unique features of electronic formats, such as interactivity, multimedia or integration with dynamic content (for example, spares prices, stock levels and machine status). While the machine tool industry takes a conservative approach to electronic TSD, the aerospace industry has been using such technologies for integrated logistic support for over 20 years. Litman (1996) has identified significant benefits from the use of electronic documentation to support complex weapons systems, such as reductions in mean time to repair of 50\%, increases in the accuracy (quality) of repair of $40 \%$ and reductions in training time of $30 \%$. For a flexible manufacturing system with typical downtime of 40\% (Somers and Gupta, 1991) such improvements could raise productivity significantly. It was the recognition of the opportunity for technology transfer that led to the scoping study that is described in this paper.

The aim of the study was to investigate the extent to which techniques used to create TSD in the aerospace industry might be applied to the manufacturing machinery sector during the next five years. The study was part-funded by the DTI under its ICT Carrier programme, with the balance of the funding from the study team comprising Cranfield University, the Advanced Manufacturing Technology Research Institute (AMTRI), the Manufacturing Technologies Association (MTA), GKN Aerospace Engineering Services, Domino Printing Sciences and Electroimpact UK. This paper presents some of the background to the scoping study drawn from literature and the experience of the 
study team, followed by a description of the study

methodology and presentation of results. The study comprised interviews with stakeholders, a questionnaire survey and a workshop.

\section{Trends in manufacturing}

The current interest in lean manufacturing has placed greater emphasis on the availability of production machinery and therefore the service provided by those who maintain the machinery. The technical complexity of today's machine tools means that they must be supported by comprehensive, accurate and highly usable documentation. According to AMTRI (2000), four trends will change the nature of TSD for machine tools.

1. The trend for machinery manufacturers to become service providers, retaining ownership of the machinery and assuming responsibility for its availability and support.

2. The trend towards modularity in the design of machinery. This 'mass customisation' approach allows manufacturers to respond to market requirements rapidly and cost effectively.

3. The continuing skills shortages throughout manufacturing, that may lead to greater emphasis on effective documentation of equipment and procedures as well as better quality training of new recruits.

4. The trend towards Internet-based remote support of machinery.

These trends raise several related questions. If machinery manufacturers become service providers and therefore users of their own TSD, how will this change the approach that they take to the authoring of such documents? How do the related concepts of modularity and mass customisation apply to product documentation? What is the appropriate mix of classroom training and on-the-job technical support and what is the best way to impart technical knowledge to maintenance workers? To what extent will tomorrow's machine tools be supported remotely and what role will web technologies such as those described by Wang et al. (2004), play in machine fault diagnosis? 
In addition to these trends, the globalisation of manufacturing places a premium on the accurate translation of complex technical documents and on the use, where possible, of language-independent methods of communication, such as multimedia.

\section{Servicisation}

The tendency of some manufacturers to re-position themselves as service providers has been called 'servicisation' (Howells, 2003). Perhaps the best-known example of servicisation is the transition of both General Electric and Rolls-Royce from selling aircraft engines to selling a 'power by the hour' service that includes leasing, maintenance, repair, inventory management and facilities support (DTI, 2000). Wise and Baumgartner (1999) suggest nine metrics that indicate whether a transition towards selling a service rather than a product would be profitable, including the ratio of installed base to new product sales. By this metric it makes sense for a locomotive manufacturer to position itself as a service provider, but not a manufacturer of video cassette recorders. It is not yet clear to what extent machine tool manufacturers perceive themselves as service providers, but if they do decide to follow the servicisation trend, the decision will surely affect the way in which they manage the creation and use of TSD.

\section{Technical documentation for machine tools}

One of the first objectives of the scoping study was to canvass the views of today's machine tool designers. When asked his view on the relevance of electronic TSD to machine tools, a designer commented that at present there is no coherent electronic library of information to assist designers. Such a library could be very useful, in his view, if it contained:

- Basic machinery design data

- Relevant ISO standards

- Online technical support of the standard machine components

- Health and safety information

- Details of relevant research. 
MTA members confirmed that most current TSD for machine tools is provided as hardcopy. One reason for this is that at their customers' premises the equipment for reading electronic information is usually remote from the point of machine use or even 'off-limits' to factory workers. Electronic TSD is usually available only for machines in which the controller is a PC that also provides the human-machine interface. The main problems associated with paper documentation are issue control, comprehension, translation and speed of access. It was felt that any electronic solution to these problems must be cost-effective and take no longer to create documents than current methods.

\section{Technical documentation in the aerospace sector}

The emergence of electronic TSD in the aerospace industry was driven by the need to support highly complex products over an extended life cycle, the duration of which is unknown at the time of design. The industry achieved this through the development of documentation standards that provide consistent structure and content element codification which are essential for the efficient compilation, identification, management and integration of data in a computerised environment.

A key standard in the history of technical documents for civil aircraft was the Air Transport Association (ATA) 100 specification, which mandated the layout of information in a precise and consistent sequence including chapterisation by system, sub-system and component, the use of page blocks for types of information and a consistent arrangement and sequence of chapter contents. Table 1 shows the ATA 100 standard chapter headings and Table 2 that ATA 100 standard page blocks by subject. Within this system, for example, section 49-10-10 refers to the fuel control unit (component level) which is part of the power generation sub-system which in turn is part of the auxiliary power system. In this case since the component is itself an assembly, the system is used to further index the sub-assemblies and the parts within each of these.

$<$ Place table 1 here $>$

$<$ Place table 2 here $>$

A range of document standards was developed to describe the codification of tasks 
and sub-tasks below page block level. These standards have now been incorporated into the ATA specification. The ATA system has allowed the civil aviation industry to achieve a high degree of data linkage without the cost penalty of a formal integrated logistic support system.

The style and format of technical documentation for defence systems, including aircraft, was a haphazard affair until the late 1980s. The US Department of Defense launched the CALS (Computer-aided Acquisition \& Logistic Support) initiative in the mid-1980s to address some of the anomalies and inconsistencies of TSD. ATA 100 and its derivatives have now been adopted as the de facto documentation standard within CALS for all new military aircraft programs. European military authorities developed their own version of CALS and a commonly-applied specification for technical manuals, AECMA S1000D, has gradually replaced all earlier national variants. For air vehicles, the data module code system of AECMA S1000D is based on the ATA codification system. There is now therefore, a degree of uniformity between TSD for civil and military aircraft.

\section{Application of aerospace practice to machine tools}

The ATA 100 system is clearly comprehensive enough in principle to cover all the information types needed for machine tool documentation. One could imagine a standard chapterisation scheme for machine tools that covered such systems as the spindle drive, axis drives, control systems, frame, coolant system, lubrication system and all their associated sub-systems and components. As well as support documentation, machinery manufacturers are currently obliged to provide a structured technical file in order to comply with the machinery directive and to obtain a CE mark. A content management system could be specified to meet existing requirements as well as the proposed standard chapters and page blocks. At least one large user of machine tools, the Ford Motor Company, has introduced its own standardised section headings for production machinery and has required machinery suppliers to comply with this system. However, if machinery users act independently in this way, they will inevitably design different chapterisation schemes, even if they are similar in principle. It may be possible for a machinery supplier to map their chosen structure onto that favoured by a 
user and so re-purpose technical support documentation to suit a range of customers, however it would surely be more cost-effective for the machine tool industry to act together to standardise the structure and layout of their technical documentation, as the aerospace industry has.

In addition to the structure and meaning of technical documentation, the CALS and AECMA S1000D standards deal with the storage and exchange of digital information. It is likely that despite the benefits of standardisation on data formats such as SGML for structured text and CGM for vector graphics, the complexity of such standards and the cost of compliant authoring tools would make this approach impractical for machine tool builders at present. However, if the cost of authoring tools for structured documentation reduces, this may well prove to be a suitable approach for the machine tool industry. An example of such a tool might be a content management system for creation and maintenance of a web site and other documents that re-use the same content.

\section{Interviews with stakeholders}

The project sought the opinions of a range of stakeholders who could help to form a view of the current use of electronic TSD in the aerospace industry and the scope for transfer. The project team identified four interviewees from each of the following types of organisation:

1. Suppliers of authoring tools for electronic TSD

2. Users of authoring tools for electronic TSD (from various industries)

3. Aerospace users of electronic TSD

4. Manufacturing machinery suppliers

5. Machinery users and maintainers.

The interviews confirmed that technical authors in the aerospace industry take a fundamentally standards-based approach. This has resulted in the dominance of two software tools; Adobe Framemaker and Arbortext Epic, with many associated tools from third parties. By comparison, technical authors within the manufacturing machinery sector use cheaper, less powerful tools that are more generic and less 
focused on the creation of structured documentation, the re-use of content or adherence to information standards. Whether the manufacturing machinery sector will adopt documentation practices from today's aerospace authors may depend largely on the development and acceptance of information standards. There are signs that this is happening in the pharmaceutical, food and electronics industries, so machinery builders who serve these industries may, in future, be seen as 'early adopters'. Authoring tool vendors and technical authors identified general trends towards online information, with the content management features of these tools being used to allow easy updates and re-use of content. Of particular relevance to the machinery sector is a trend towards the delivery of online information through the human-machine interface at the controller. Users of electronic TSD within the aerospace industry 
indicated that there is scope for improvement of the documents, citing poor usability, the cost of display hardware and its poor portability as particular problems. PDF is the most commonly used presentation format for technical support documents, although the preference of the defence sector of the aerospace industry is for fully-functional Interactive Electronic Technical Manuals, as described by Setchi and White (2003). Authors of technical support documentation for manufacturing machinery agreed that from their customers' perspective, ease of use is most important, but stated that ease of information access and information accuracy are also very important. The four machinery users confirmed these views.

Technical authors for manufacturing machinery also felt that the most important benefits of enhanced document creation methods would be reduced costs and enhanced customer satisfaction. Only one of the four authors interviewed was using software designed specifically for the creation of structured documentation, the others choosing generic products such as Microsoft Office and various computer-aided design (CAD) tools. As with their counterparts in the aerospace sector, technical authors from the manufacturing machinery sector also use PDF for presentation of the majority of their electronic technical documents.

\section{Questionnaire survey}

The survey of members of the MTA comprised thirteen questions. These explored existing approaches to TSD for manufacturing machinery, and likely developments over the next five years. Of the 47 questionnaires sent to members, only seven were returned. This response rate of only $15 \%$ may reflect the current priorities of a troubled industry.

Notwithstanding the poor response to the questionnaire, the survey confirmed some earlier findings of the scoping study, such as the importance of a low cost approach to documentation and the widespread use of CAD and generic office tools to author technical documents (Figure 1).

$<$ Place figure 1 here>

An indication of the relatively small technical documentation activity in the machine tool companies surveyed is the small number of dedicated technical authors employed. Four of the survey respondents do not employ anybody dedicated to technical authoring and only one respondent employs two or more such staff (see 
Figure 2).

$<$ Place figure 2 here $>$

Despite this, there are signs that some machine tool manufacturers expect to provide more interactivity (a feature only possible with electronic documents) for their customers in future. This is despite their view that there is little customer demand for this and their feeling that that technical support documentation is not a source of strong competitive advantage.

There was broad agreement that the most important feature of electronic TSD to customers would be the provision of step-by-step multimedia guidance for routine maintenance and set-up operations. Machinery builders attach significant importance to three features of electronic technical documentation; greater control of document revision level, re-use of information and reduced time to market.

Based on the questionnaire responses, one can conclude that there may be a small trend towards electronic TSD for machine tools, especially online technical assistance. However, machine tool companies are very unlikely to invest significant resources in the development of electronic technical documentation beyond that required to keep up with the competition and the modest expectations of their customers.

\section{Workshop}

The aim of the one-day workshop was to stimulate and capture discussion among experts from the manufacturing machinery and machine tool industries, with respect to electronic technical documentation. Twenty-four delegates attended the workshop. Following presentations on the results of the project so far, delegates were split into three groups. Each group was each asked to consider the following three questions:

1. What are the drivers and constraints relating to the adoption of e-support technologies?

2. What are the types and relative priorities of information relevant to e-support?

3. What steps should the machinery sector take to harness e-support technology to current business objectives?

\section{Drivers and constraints}

Workshop delegates gave mixed responses to this question. On one hand, the need to reduce cost was emphasised here and throughout the workshop, to the extent that the 
impression given was of an industry struggling for survival. On the other hand, a significant majority of factors driving the adoption of e-support technologies were related to the need to increase quality. It is therefore felt that the industry will adopt e support technologies when and if managers see them delivering a better service to the customer, without incurring a cost penalty. The main factor constraining the adoption of e-support technologies is the absence of suitable standards for hardware, software and information. Other constraints were felt to be the cost of adoption and lack of management commitment.

\section{Types of information for e-support}

It was agreed that the three most important types of information that should be provided using e-support technologies are, in order of priority:

1. Operating and safety information

2. Maintenance procedures

3. Fault diagnostics.

Delegates identified other categories of suitable information such as service information, spare part details (including prices) and design information, but there was little agreement on relative priorities.

\section{Next steps that the sector should take}

Delegates agreed that the first step that needs to be taken by the industry to harness e support technologies is to form a working party to identify standards for information content and format and the software tools that will be needed to create and manage electronic TSD. It was suggested that a questionnaire should be used to form a detailed picture of customer requirements. The second step is to investigate a mechanism by which organisations within the manufacturing machinery industry can collaborate to create and manage electronic TSD to mutual advantage, without compromising the competitive position of any organisation. The third step is to prepare an implementation plan and disseminate this throughout the industry, perhaps using a technology demonstrator to validate the plan and educate the producers of manufacturing machinery and their customers about the best use of e-support technologies. 


\section{Conclusions}

If machine tool manufacturers re-position themselves as service providers, they will benefit from the adoption of some of the information technologies in use today in the aerospace sector. This project has shown that the machine tool industry currently perceives low customer demand for electronic support documentation. If this is true, one explanation might be that whereas the pursuit of lower life-cycle costs has driven the adoption of electronic TSD in the aerospace industry, what matters much more to machine tool users are functionality and low purchase price. However this need not be a constraint to the adoption of electronic TSD by the machine tool industry as long as machinery manufacturers see electronic TSD as a means of lowering the cost of regulatory compliance as well as minimising life-cycle costs for their customers. If and when lower cost of ownership of machine tools does become a selling point, then it will be rational for manufacturers to collaborate in the development of information standards within the industry and to integrate electronic TSD into their products. At present, many technical authors in machine tool manufacturing are using inappropriate authoring tools, and this research suggests that the adoption of more suitable tools and techniques would allow them to reduce the cost of creating and maintaining electronic TSD. The core content of such documents is likely to comprise operating and safety information, maintenance procedures and fault diagnostics. Perhaps the most likely future technology transfer scenario is the gradual adoption of some of the documentation practices from the aerospace sector, driven by the spread of information standards created by global regulatory bodies. The industry could prepare for the future by supporting the development of information standards and exploring the best use of electronic TSD, perhaps through a technology demonstrator.

\section{References}

AMTRI (2000), 'Manufacturing Machinery Foresight, Final report for the Department of Trade and Industry', AMTRI reference number: 3rs6049/4, www.amtri.co.uk (2000), accessed on 15th October 2002. Crowder, R., Hall, W., Heath, I. and Wills, G. (2000) 'Industrial strength hypermedia: design, implementation and application', International Journal of Computer Integrated Manufacturing, Vol. 13, No. 3, pp. 173-186.

DTI (2000), 'UK Manufacturing: We can make it better', Final Report of Manufacturing 2020 Panel, Department of Trade and Industry.

Greenough, R.M., Fakun, D. and Kay, J.M. (2001), 'Development of a digital manual for a manufacturing system - a case study', Integrated Manufacturing Systems, Vol. 12, No. 6 , pp. 387-393. 
Howells, J. (2003), 'Innovation and Services: The combinatorial role of services in the knowledge-based economy' In: Proceedings of the Conference on New Trends and Challenges of Science and Technology Innovation in a Critical Era, Taipei, 30-31 October 2003, pp. 16-1 - 16-22.

Litman, E.F. (1996), 'CALS - a strategy for business engineering' Logistics Information Management, Vol. 9 , No.1, pp. 18-23.

Setchi, R. and White, D. (2003), 'The development of a hypermedia maintenance manual for an advanced manufacturing company', International Journal of Advanced Manufacturing Technology, Vol. 22, pp. 456-464. Somers, T.M. and Gupta, Y.P. (1991), 'An examination of an engine manufacturing plant's downtime and production standards', International Journal of Operations and Production Management. Vol. 11, No. 5, pp. 2238.

Wang, J.F., Tse, P.W., He, L.S. and Young, R.W. (2004), 'Remote sensing, diagnosis and collaborative maintenance with Web-enabled virtual instruments and mini-servers', International Journal of Advanced Manufacturing Technology, Vol. 24, pp. 764-772.

Wise, R. and Baumgartner, P. (1999), 'Go Downstream: The new profit imperative in manufacturing', Harvard Business Review, September-October 1999, pp. 133-141.

Table 1: ATA 100 specification standard chapters

Table 2: ATA 100 specification standard page blocks

Figure 1: Tools used to produce technical support documents

Figure 2: Staff dedicated to technical authoring in machine tool companies 
Table 1: ATA 100 specification standard chapters

\begin{tabular}{|c|c|c|c|}
\hline Chap. & Subject & Chap. & Subject \\
\hline 00 & Air Vehicle General & 51 & Standard Practices - Structures \\
\hline 04 & Airworthiness Limitations & 52 & Doors \\
\hline 05 & Time Limits/Maintenance Checks & 53 & Fuselage \\
\hline 06 & Dimensions and Areas & 54 & Nacelles and Pylons \\
\hline 07 & $\begin{array}{l}\text { Lifting, Shoring, Recovering and } \\
\text { Transporting }\end{array}$ & 55 & Stabilizers \\
\hline 08 & Levelling and Weighing & 56 & Windows and Canopies \\
\hline 09 & Handling and Taxiing & 57 & Wings \\
\hline 10 & Parking and Mooring & 60 & Standard Practices - Propeller or Rotor \\
\hline 11 & Placards and Markings & 61 & Propellers and Propulsors \\
\hline 12 & Servicing & 62 & Main Rotors \\
\hline 14 & Air Vehicle Loading and Offloading & 63 & Main Rotor Drives \\
\hline 15 & Aircrew Information & 64 & Tail Rotor \\
\hline 16 & Change of Role & 65 & Tail Rotor Drive \\
\hline 18 & $\begin{array}{l}\text { Vibration and Noise Analysis and } \\
\text { Attenuation }\end{array}$ & 66 & Folding Blades and Pylon \\
\hline 20 & Standard Practices - Airframe Systems & 67 & Rotors Flight Control \\
\hline 21 & Environmental Control & 70 & Standard Practices - Engine \\
\hline 22 & Auto Flight & 71 & Power Plant \\
\hline 23 & Communications & 72 & Engine \\
\hline 24 & Electrical Power & 72 & $\begin{array}{l}\text { Engine turbine/turboprop - Ducted } \\
\text { fan/Unducted fan }\end{array}$ \\
\hline 25 & Equipment and Furnishings & 72 & Engine Reciprocating \\
\hline 26 & Fire Protection & 73 & Engine Fuel and Control \\
\hline 27 & Flight Controls & 74 & Ignition \\
\hline 28 & Fuel & 75 & Air \\
\hline 29 & Hydraulic Power & 76 & Engine Controls \\
\hline 30 & Ice and Rain Protection & 77 & Engine Indicating \\
\hline 31 & Indicating and Recording Systems & 78 & Exhaust \\
\hline 32 & Landing Gear & 79 & Oil \\
\hline 33 & Lights & 80 & Starting \\
\hline 34 & Navigation & 81 & Turbines \\
\hline 35 & Oxygen & 82 & Water Injection \\
\hline 36 & Pneumatic & 83 & Accessory Gearboxes \\
\hline 37 & Vacuum & 84 & Propulsion Augmentation \\
\hline 38 & Water and Waste & 91 & Charts and Diagrams \\
\hline 41 & Water Ballast & 93 & Surveillance \\
\hline 43 & Tactical Communications & 94 & Weapons Systems \\
\hline 45 & Central Maintenance System (CMS) & 95 & Crew Escape and Safety \\
\hline 46 & Systems Integration and Display & 96 & Missiles, Drones and Telemetry \\
\hline 47 & Liquid Nitrogen & 97 & Image Recording \\
\hline 48 & In-Flight Refuelling Tanker & 98 & $\begin{array}{l}\text { Meteorological and Atmospheric } \\
\text { Research }\end{array}$ \\
\hline 49 & Airborne Auxiliary Power & & \\
\hline
\end{tabular}


Table 2: ATA 100 specification standard page blocks

\begin{tabular}{|l|c|}
\hline \multicolumn{1}{|c|}{ Subject } & Page Block Numbers \\
\hline Description and Operation & $1-99$ \\
\hline Fault Isolation & $101-199$ \\
\hline Maintenance Practices & $201-299$ \\
\hline Servicing & $301-399$ \\
\hline Removal and Installation & $401-499$ \\
\hline Adjustment and Test & $501-599$ \\
\hline Inspection and Check & $601-699$ \\
\hline Cleaning and Painting & $701-799$ \\
\hline Repairs & $801-899$ \\
\hline
\end{tabular}


Figure 1: Tools used to produce technical support documents

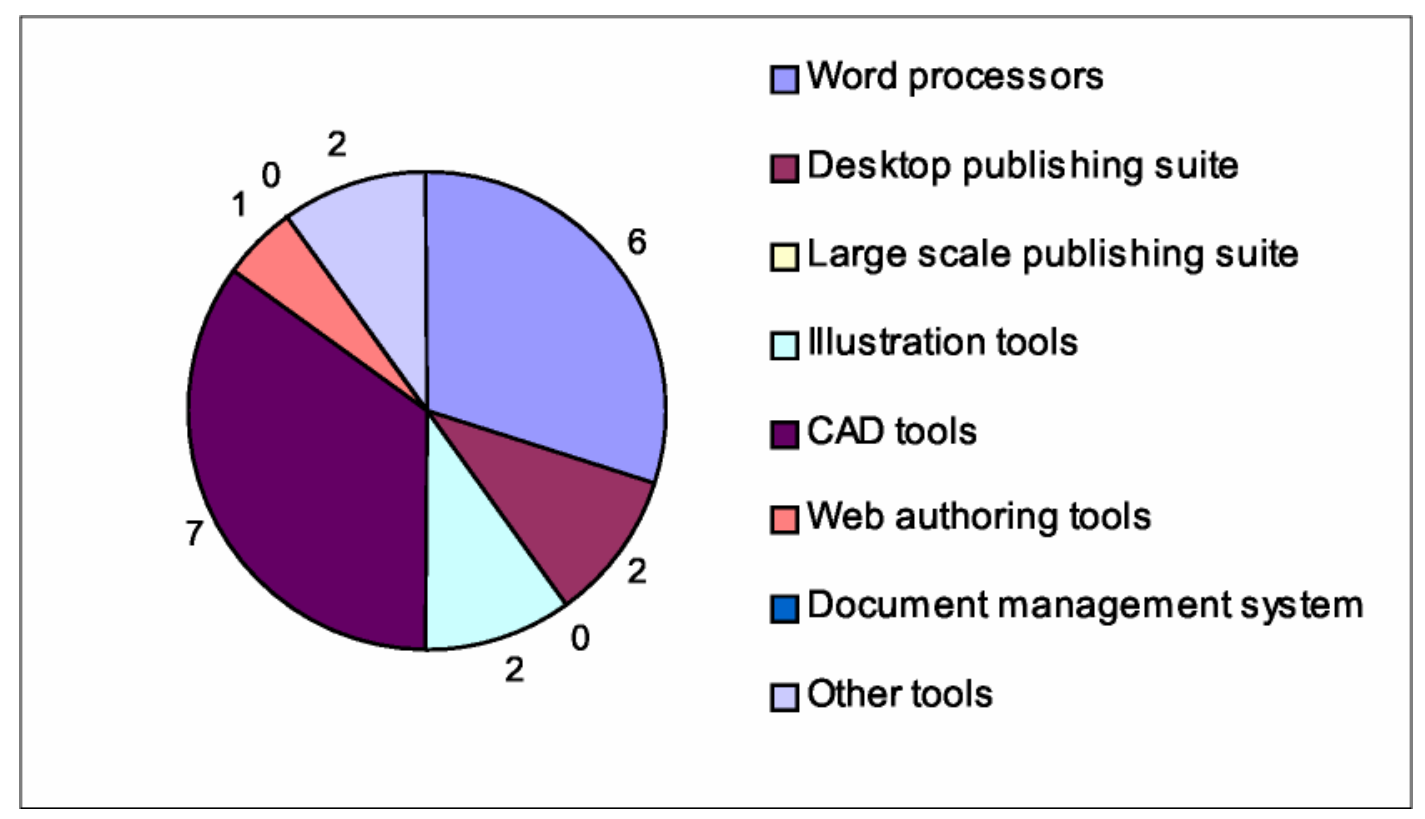


Figure 2: Staff dedicated to technical authoring in machine tool companies

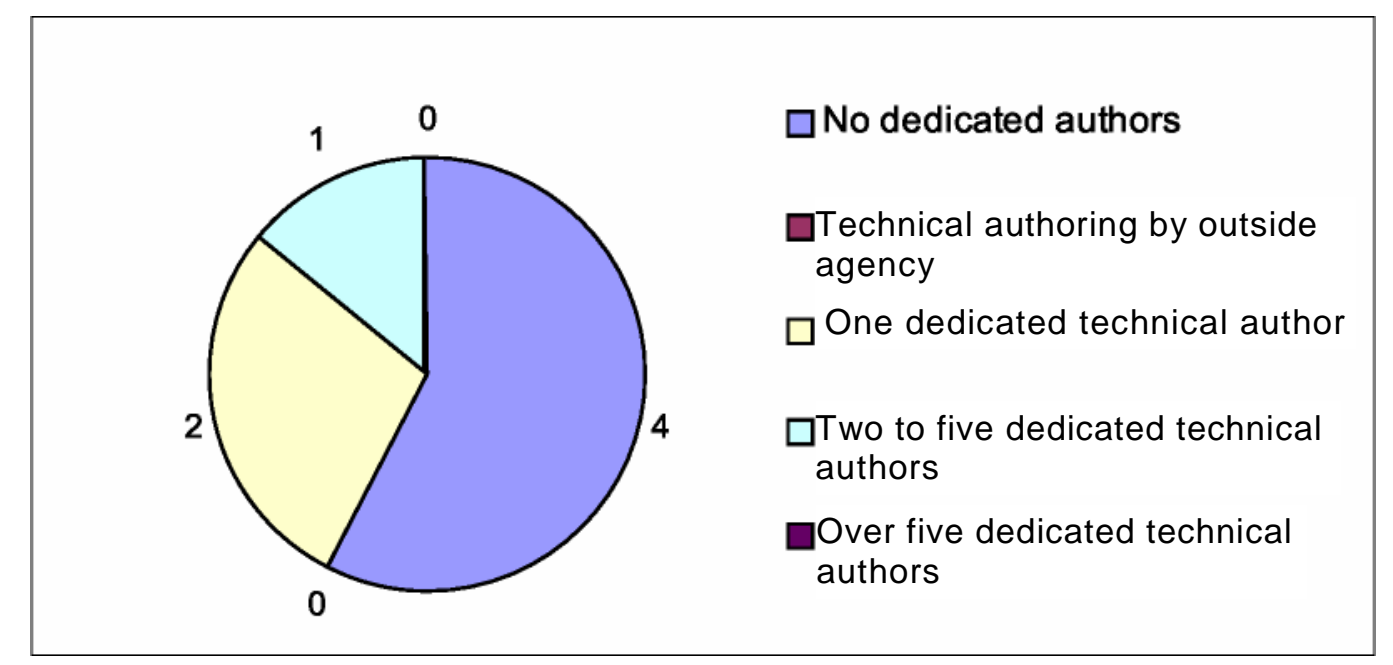

